\title{
Glycerol-derived solvents: Synthesis and Properties of symmetric glyceryl diethers
}

\author{
Alejandro Leal-Duaso, ${ }^{a b}$ Pascual Pérez, José A. Mayoral, ${ }_{a b}^{a b}$ José I. García, ${ }^{a}$ Elisabet Pires, ${ }^{a, b}$ \\ • Instituto de Síntesis Química y Catálisis Homogénea (ISQCH) CSIC- Universidad de Zaragoza. \\ C/ Pedro Cerbuna 12. 50009 Zaragoza (Spain) \\ • Departamento de Química Orgánica. Facultad de Ciencias. Universidad de Zaragoza. C/ Pedro \\ Cerbuna 12. 50009 Zaragoza (Spain)
}

· Departamento de Química Física. Universidad de Zaragoza. Calle Pedro Cerbuna, 12. 50009

Zaragoza (Spain).

KEYWORDS renewable solvents, glycerol, ethers, properties

\section{Corresponding Author}

Elísabet Pires. E-mail: epires@unizar.es /ORCID 0000-0002-2676-8814

e-mail addresses:

Alejandro Leal-Duaso: alduaso@ unizar.es

Pascual Pérez: pascual@unizar.es

José Antonio Mayoral: mayoral@unizar.es

José Ignacio García: jig@unizar.es 


\section{ABSTRACT}

Herein we report a systematic study of the synthesis of symmetric glyceryl diethers from epichlorohydrin and different alcohols. Several inexpensive alkaline hydroxides were tested and total conversions of epichlorohydrin achieved. Although high yields of the desired products were possible, the final selectivity of the reaction depends strongly on the alcohol used. Eleven symmetric glyceryl diethers were prepared employing this synthetic methodology and, in order to determine their usefulness as solvents, their physicochemical properties (density, dielectric permittivity, refractive index, viscosity, surface tension and boiling point) were measured and compared with those for similar conventional solvents. The results obtained prove the utility of these compounds as a green alternative to solvents obtained from non-renewable sources.

\section{INTRODUCTION}

In the recent years, Green Chemistry has become an important consideration when designing new synthetic chemical processes. Most industrial chemical processes and product formulations rely on the use of conventional organic solvents. However, it is known that such solvents come from non-renewable petrochemical sources, and sometimes present serious drawbacks, such as ecotoxicity, flammability and volatility. When Paul Anastas and John Warner, the "fathers" of Green Chemistry, enunciated their "12 Green Principles", they stated the need to avoid the use of solvents, which is quite difficult in the majority of chemical processes, or to use benign solvents as far as possible.' These alternative solvents should present some favorable properties such as biodegradability, availability from renewable sources and low toxicity, volatility, flammability and cost. 
Oils appear to be a readily available renewable raw biomaterial ${ }^{2-4}$ that can provide fatty esters or acids and glycerol. Glycerol is normally produced as a by-product in the oleochemical industry and its valorization is an important issue from a circular economy point of view. As such, the use of glycerol and its derivatives as possible renewable solvents has attracted great attention. ${ }^{610}$ Carbonates, ketals, esters and ethers derived from glycerol have already been used in many different applications as fuel additives, humectants, plasticizers, surfactants, etc.," and of these, glyceryl ethers present very interesting properties as alternative solvents due to their chemical stability, moderate reactivity, low acute ecotoxicity'1-14 and tunable physicochemical properties, which can be modified simply by changing the number, size, substitution and nature of their substituents. ${ }^{15-19}$

Various attempts to design effective synthetic methodologies for glycerol-derived ethers have been reported to date. Thus, in 2015 Lemaire et al. reviewed all the different approaches for the production of glyceryl ethers. ${ }^{20}$ The a priori easiest synthetic strategy, starting from glycerol, usually suffers from the drawback of providing low product selectivities, ${ }^{2,2}{ }^{12}$ with mixtures of mono-, di- and triethers being obtained in variable proportions. Some attempts have been made to solve this problem by using Lewis acid catalysts in the reaction of glycerol with short alkyl alcohols. In this work, glyceryl monoethers are obtained as the major products in a maximum yield of $60 \%{ }^{23}$ Despite being the most attractive option, the low selectivity reduces the practical interest of this approach for producing diethers. However, glycerol is easily transformed into platform molecules with high yields even on an industrial scale, and these molecules are attractive intermediates in the synthesis of glycerol derivatives with higher selectivity. Some of these molecules, which are produced in high amounts by the chemical industry, are glycidol (2,3epoxy-1-propanol), 3-chloropropane-1,2-diol and epichlorohydrin (1-chloro-2,3-epoxipropane). 
In general, glycidol or 3-chloropropane-1,2-diol are used for the synthesis of glyceryl monoethers (GMEs). To date, the most effective methodology for the synthesis of glyceryl monoethers with high yields involves reaction of the appropriate platform molecule with the corresponding alkoxide formed from the desired alcohol and metallic sodium. ${ }^{15}$ However, use of this reagent goes against some of the key principles of Green Chemistry as regards the safety of the process, its toxicity and the generation of unnecessary residues. Over the past two years, three interesting papers have been published concerning the synthesis of GMEs from glycidol..$^{2+26}$ These studies described the production of GMEs in high yields and with high selectivity.

When the synthesis of glyceryl symmetric diethers (GDEs) is envisaged, the use of epichlorohydrin as building block is preferred as this platform molecule is now readily available thanks to the new Solvay synthesis. ${ }^{27}$ Of the few studies dealing with the synthesis of GDEs, the most relevant results involve the use of $\mathrm{NaH}$ at high temperature $\left(100{ }^{\circ} \mathrm{C}\right)$ or several reaction steps..$^{20}$

Herein we present a readily effective methodology for the synthesis of symmetric glyceryl diethers [R.0.R] starting from epichlorohydrin and different alcohols, thereby avoiding the use of other hazardous reagents, such as sodium, or an excess of epichlorohydrin or any additional cosolvent.

As mentioned above, the main aim of this research was to provide an environmentally suitable alternative to conventional solvents, therefore the main physicochemical properties of symmetric glyceryl ethers are also reported and compared with those for traditional solvents, thus making selection of the alternative glycerol-derived solvent easier. 


\section{EXPERIMENTAL SECTION}

All products were characterized by ${ }^{1} \mathrm{H},{ }^{13} \mathrm{C}$, and ${ }^{10} \mathrm{~F}$ NMR spectroscopy, and by HRMS. Gas chromatography analyses were carried out using an HP 7890 Series II gas chromatograph equipped with a FID detector and a Zebron ZB-5HT Inferno column $(30 \mathrm{~m} \times 0.25 \mathrm{~mm} \times 0.25$ $\mu \mathrm{m})$. NMR spectra (DMSO-d ${ }_{6}, \delta$ ppm, J Hz) were obtained using a Bruker AV-400 instrument with TMS as standard. MS spectra were obtained using a Bruker MicroTof-Q spectrometer with electrospray ionization.

Epichlorohydrin, diglyme, anisole, octanol, and LiOH were purchased from Sigma-Aldrich. Methanol, ethanol, isopropanol, $\mathrm{KOH}$ and $\mathrm{NaOH}$ were purchased from Scharlab. 1-Butanol, trifluoroethanol (TFE), 1-hexanol, 2-ethylhexan-1-ol, and phenol were purchased from Alfa Aesar, and 1-propanol and 1-pentanol from Acros. Alcohols were dried by refluxing over calcium hydride and distilled prior to use. The purity of hydroxides was determined by titration using potassium hydrogen phthalate as titrating agent.

\section{Synthesis of symmetric glyceryl diethers 4}

The corresponding alcohol $(65 \mathrm{mmol})$, base $(6.1 \mathrm{mmol})$, and diglyme or anisole as internal standard $(15 \% \mathrm{w} / \mathrm{w}$ with respect to epichlorohydrin) were placed into a round-bottomed flask, then the reaction mixture was stirred at the desired temperature $\left(65,45\right.$, or $\left.25^{\circ} \mathrm{C}\right)$ under argon until total dissolution of the base. Epichlorohydrin $(4.35 \mathrm{mmol})$ was then added dropwise. All reactions were monitored by GC until total consumption of epichlorohydrin, at which point the reaction was quenched with $\mathrm{HCl} 0.3 \mathrm{M}$ and the salts filtered off. Finally, unreacted starting alcohol was distilled and recovered and the resulting glyceryl diether was purified by vacuum distillation. Conversions and yields during the reaction were determined by GC and checked by 
'H NMR at the end of the reaction. Synthetic reactions were scaled up to 2 mol of epichlorohydrin $(\mathrm{ECH})$ in order to obtain ca. $100 \mathrm{~g}$ of product.

\section{Synthesis of alkyl glycidyl ethers 3}

The methodology was the same as for the synthesis of $\mathbf{4}$, but the optimized reaction parameters were $65{ }^{\circ} \mathrm{C}$, 30:1 alcohol to epichlorohydrin molar ratio, and an equimolecular amount of base/epichlorohydrin. Once the maximum glycidyl ether yield had been achieved, the reaction was quenched with $\mathrm{HCl} 0.3 \mathrm{M}$ and the salts filtered off. Finally, the unreacted starting alcohol was distilled under vacuum and recovered, and the product was purified by column chromatography prior to characterization.

\section{Measurement of experimental properties}

Density and sound propagation speed. Both properties were determined simultaneously using an Anton Paar DSA $5000 \mathrm{M}$, with an internal Peltier thermostat at $\pm 0.001 \mathrm{~K}$. After appropriate calibration, the sample was introduced into a U-shaped glass tube and the density obtained from its frequency of vibration with an uncertainty of $\pm 5 \times 10^{-3} \mathrm{~kg} \mathrm{~m}^{-3}$. Correction due to the kinematic viscosity of the liquid was performed automatically. The sound propagation speed of the sample was calculated with an uncertainty of $\pm 0.1 \mathrm{~m} \mathrm{~s}^{-1}$ by passing sound waves through the cell.

Polarity. The dielectric permittivity was measured using a WTW (DM01) dipolemeter (Kahlsico) at $2 \mathrm{MHz}$. Two thermostatted cylindrical condensers were used to cover the full range of experimental data (cell DFL2 for the range of 1-7 and cell MFL2/MS for 6-14). Both cells were previously calibrated with high purity reference liquids. The relative uncertainty in the dielectric values is estimated to be better than $0.05 \%$. Finally, with the dielectric constant and other experimental data, an average dipole moment $\left\langle\mu^{2}\right\rangle^{12}$ was calculated for every liquid (in Debye) using the Onsager equation (1). ${ }^{28}$ 


$$
\left\langle\mu^{2}\right\rangle=\frac{9 k T}{4 \pi N_{A}} \cdot \frac{M}{\rho} \frac{\left(\varepsilon-n_{D}^{2}\right)\left(2 \varepsilon+n_{D}^{2}\right)}{\varepsilon \cdot\left(n_{D}^{2}+2\right)^{2}}
$$

Where $k$ is Boltzmann's constant, T the temperature in $\mathrm{K}, N_{A}$ Avogadro's number, $M$ the molar mass, $\varepsilon$ the dielectric permittivity, $n_{D}$ the refractive index and $\varrho$ the density.

Refractive index. An Abbe ZUZI 315 refractometer with controlled temperature and a sodium lamp was used to measure refractive indices with an uncertainty of \pm 0.0001 .

Viscosity. Three Ubbelohde viscometers with suspended ball level and intermediate flow time were used so as to cover the entire range of experimental values (instruments 50103/0c, 50110/I and 50111/Ia, with constants, $k$, of $0.002835,0.01029$ and $0.04957 \mathrm{~mm}^{2} \mathrm{~s}^{-2}$ respectively. The viscometers were placed in a thermostatted bath. Flow time was measured at least three times with differences not greater than $\pm 0.3 \mathrm{~s}$. Viscosities were calculated with an uncertainty of $0.6 \%$ using equation 2 :

$$
v=k\left(t-\Delta_{H C}\right)
$$

where $v$ is the kinematic viscosity, $k$ the viscometer constant, $t$ the average flow time (in seconds) and $\Delta_{H C}$ the kinetic energy correction.

Surface tension. A Lauda TVT-2 drop volume tensiometer was used to obtain the surface tension of solvents at a fixed temperature with a relative uncertainty not worse than $0.5 \%$. A Lauda E-200 thermostat allowed the sample temperature to be maintained within $\pm 0.01 \mathrm{~K}$.

In all cases, the temperature was recorded using a $\mathrm{A} \Sigma \Lambda$ digital thermometer with a Pt sensor, with a resolution of $0.001^{\circ}$ and uncertainty of $\pm 0.01 \mathrm{~K}$.

Boiling points. Boiling points were determined using the onset temperature of Differential Scanning Calorimetric (DSC) analysis in a TA Instruments DSC-Q20, calibrated with indium, using micropore aluminium pans at atmospheric pressure. 


\section{RESULTS AND DISCUSSION}

For the synthesis of GDEs (4) we proposed the use of epichlorohydrin as starting material and alkaline hydroxides as base for alkoxide formation.

The synthetic process involves two sequential steps taking place in one-pot, with no isolation of the reaction intermediate $\mathbf{3}$ (Scheme 1).

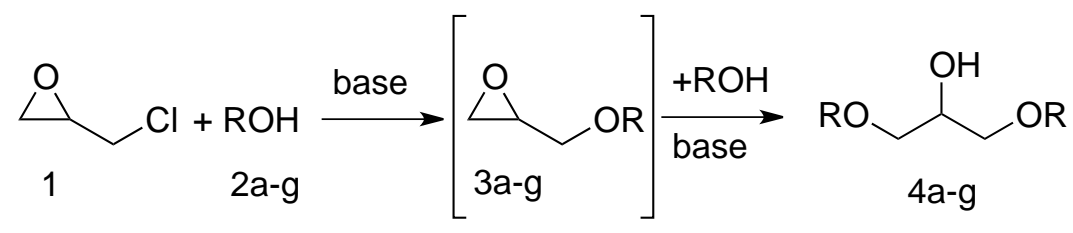

2a: $\mathrm{MeOH} \quad$ 2c: n-BuOH 2e: 2-ethylhexan-1-ol 2g: $\mathrm{PhOH}$ 2b: $\mathrm{EtOH} \quad$ 2d: ${ }^{\mathrm{P} O \mathrm{OH}}$ 2f: $\mathrm{CF}_{3} \mathrm{CH}_{2} \mathrm{OH}$ (TFE)

Scheme 1. Synthesis of symmetric glyceryl diethers 4a-g from epichlorohydrin (1) and alcohols 2a-g

As the first step implies the nucleophilic substitution of chlorine in epichlorohydrin (1), stoichiometric amounts of base are needed, whereas only catalytic amounts are required for the subsequent epoxide ring opening.

\section{Screening of the reaction conditions for the synthesis of GDEs}

The reaction parameters were first optimized using the benchmark reaction between epichlorohydrin (1) and methanol (2a), using $\mathrm{KOH}$ as base. The influence of the quantity of base, temperature, reagent concentrations and epichlorohydrin addition rate were studied.

The base/epichlorohydrin molar ratio was studied first using $\mathrm{KOH}: \mathbf{1}$ molar ratios of between 0 and 2:1. All reactions were carried out at $65^{\circ} \mathrm{C}$ and with a $\mathbf{2 a} / \mathbf{1}$ ratio of 15:1.

Figure 1 shows the epichlorohydrin conversions and products yields for both glycidyl ether intermediate $\mathbf{3 a}$ and final product $\mathbf{4 a}$. 

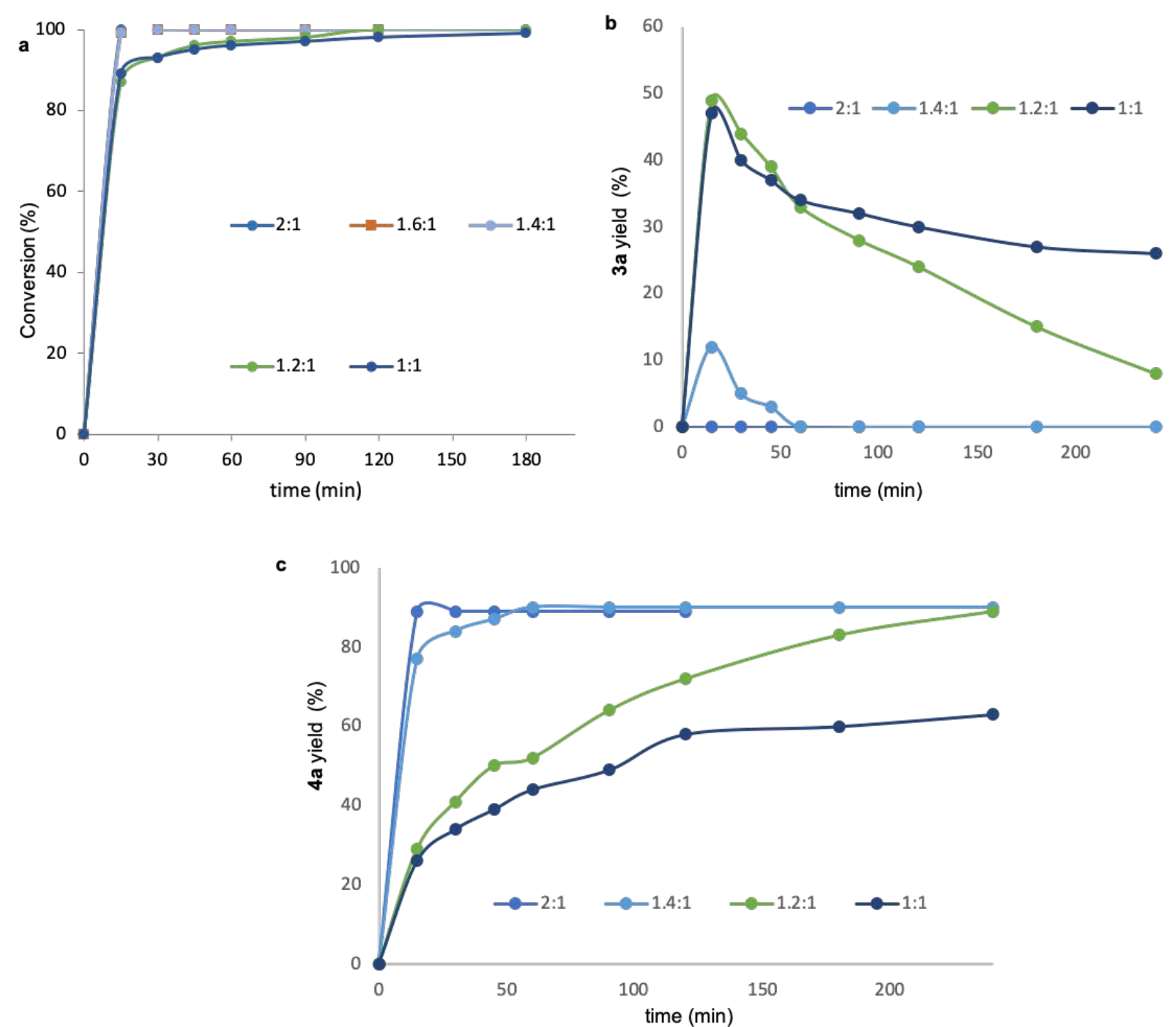

Figure 1. Optimization of the amount of base for the reaction between epichlorohydrin (1) and methanol (2a) to give $\mathbf{4 a}$

If no base is added, epichlorohydrin barely reacts (14\% conversion in 48 hours), whereas when $\mathrm{KOH}$ is added, total conversions of $\mathbf{1}$ were achieved in between 15 and $120 \mathrm{~min}$ when using a molar ratio greater than 1:1 (Figure 1a). However, the rate of conversion of glycidyl ether 3a into $4 \mathbf{a}$ is very dependent on the quantity of base (Figure 1b). Thus, when using a $\mathrm{KOH}: \mathbf{1}$ ratio of $2: 1$, no formation of the reaction intermediate $\mathbf{3 a}$ is detected 
and the desired product is obtained in only $15 \mathrm{~min}$. We are aware that the amount of base should be reduced in order to minimise salt formation and to improve the green metrics of the process, therefore several studies were carried out to progressively reduce this ratio. As can be seen in Figure 1c, longer reaction times are needed when using a KOH/1 ratio of less than 1.4:1 in order to totally convert 3a. However, ratios higher than 1.4 did not markedly improve reaction times. As such, we decided to continue the study using 1.4 mol of $\mathrm{KOH}$ per mol of epichlorohydrin. Above this, a high selectivity of $\mathbf{4 a}(90 \%)$ was achieved.

The influence of reaction temperature on the synthesis of $\mathbf{4 a}$ was studied next (Table 1), using temperatures of 65,45 and $25^{\circ} \mathrm{C}$.

Table 1. Effect of temperature on epichlorohydrin (1) conversion and yield of $\mathbf{3 a}$ and $\mathbf{4 a}$

\begin{tabular}{|c|c|c|c|c|c|c|c|}
\hline \multirow{2}{*}{$\begin{array}{l}\text { Time } \\
\text { (min) }\end{array}$} & \multicolumn{3}{|c|}{ Conversion (\%) } & \multicolumn{4}{|c|}{ Yield (\%) } \\
\hline & $65^{\circ} \mathrm{C}$ & $45^{\circ} \mathrm{C}$ & $25^{\circ} \mathrm{C}$ & $65^{\circ} \mathrm{C}$ & $45^{\circ} \mathrm{C}$ & $65^{\circ} \mathrm{C}$ & $45^{\circ} \mathrm{C}$ \\
\hline 15 & 99 & 92 & 56 & 12 & 44 & 77 & 47 \\
\hline 30 & 100 & 97 & 72 & 5 & 30 & 84 & 63 \\
\hline 45 & 100 & 100 & 78 & 3 & 21 & 87 & 76 \\
\hline 60 & 100 & 100 & 82 & 0 & 15 & 90 & 82 \\
\hline 90 & 100 & 100 & 86 & 0 & 7 & -- & 91 \\
\hline 120 & 100 & 100 & 89 & 0 & 4 & -- & 94 \\
\hline
\end{tabular}


When the reaction was carried out at $25^{\circ} \mathrm{C}$, a reaction time of more than 2 hours was required for total epichlorohydrin conversion. In contrast, when carrying out the reaction at $45{ }^{\circ} \mathrm{C}$ total conversion of 1 was achieved in $45 \mathrm{~min}$, whereas a time of 120 min was required to obtain the maximum yield of $\mathbf{4 a}$.

A temperature of $65^{\circ} \mathrm{C}$ was chosen as the most convenient as total conversions and good yields were achieved in shorter times. This decision was also based on the fact that these conditions were subsequently to be used for less reactive alcohols.

A reduction in the amount of alcohol was also envisaged. Thus, as the alcohol is used as both reagent and solvent, results above gathered were carried out with a 15:1 molar ratio of $\mathrm{MeOH}$ to epichlorohydrin $(\mathrm{ECH})$.

We now present the results using an excess of 7.5:1. An epichlorohydrin conversion of $100 \%$ was observed in $15 \mathrm{~min}$. Moreover, as expected, conversion of glycidyl ether intermediate 3a was also faster at higher concentration, although the final yield of the desired product 4a was slightly lower than when using a 15:1 proportion (84\% vs 90\%). Competitive reactions, mainly dimerization and oligomerization processes, the products of which were detected by GC, are responsible for this yield decrease.

Finally, we considered the effect of speed of epichlorohydrin (1) addition on the yield of 4a. As has been reported previously for the synthesis of GMEs, a marked influence of glycidol addition rated on the selectivity of the products was observed..$^{24}$ In our case, a slow addition of epichlorohydrin produced no significant effects on either reaction rate or product selectivity, thus confirming that this reagent does not participate in side reactions, probably due to its fast conversion.

To summarize, the standard reaction conditions finally chosen were $65{ }^{\circ} \mathrm{C}$, a $\mathrm{MOH}: \mathbf{1}$ molar ratio of 1.4:1 and an alcohol 2 to epichlorohydrin (1) molar ratio of 15:1. 


\section{Scope of the synthesis with different bases and alcohols}

In addition to $\mathrm{KOH}$, two other metal hydroxides, namely $\mathrm{LiOH}$ and $\mathrm{NaOH}$, as well as seven alcohols, were tested for the synthesis of glyceryl diethers 4 (Figure 2). In order to prepare symmetric diethers with different substitution patterns, we selected alcohols with linear alkyl chains (2a-c), branched chains (2d-e), fluorinated chains (2f), and an aromatic substituent (2g). These alcohols were selected in order to provide diethers with a range of different properties, mainly boiling point, polarity and viscosity. Various applications have been described for these diethers. Thus, $4 \mathbf{a}$ has been used as a fuel additive, ${ }^{20} \mathbf{4 c}$ has been used as a reaction medium in enzymatic synthesis, ${ }^{30}$ and $\mathbf{4 f}$ has been successfully used as a solvent in epoxidation reactions and biocatalysis. ${ }^{3132}$

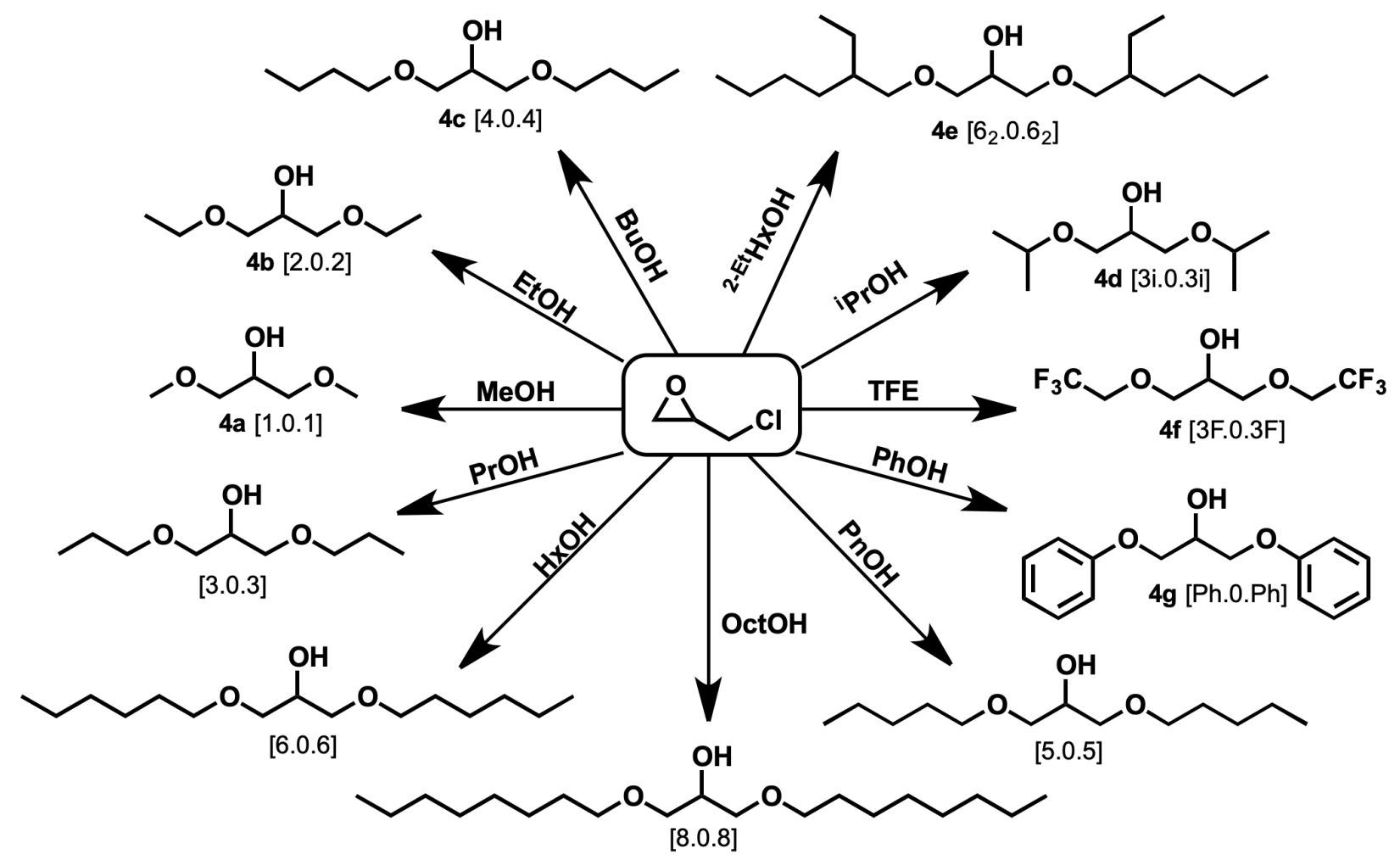

Figure 2. Structure and notation of the glyceryl diethers 4 synthesized in this work. 
Table 2. Optimized conversions and yields for the reaction of epichlorohydrin (1) with different alcohols 2 and metal hydroxides.

\begin{tabular}{l|l|c|cc|cc|cc}
\hline \multirow{2}{*}{ Entry } & \multirow{2}{*}{ Alcohol } & $\begin{array}{c}\text { Reaction } \\
\text { time }(\mathrm{h})\end{array}$ & $\begin{array}{c}\mathbf{1} \\
\text { Conv. } \\
(\%)\end{array}$ & $\begin{array}{c}\mathbf{4} \\
\text { Yield } \\
(\%)\end{array}$ & $\begin{array}{c}\mathbf{1} \\
\text { Conv. } \\
(\%)\end{array}$ & $\begin{array}{c}\mathbf{4} \\
\text { Yield } \\
(\%)\end{array}$ & $\begin{array}{c}\mathbf{1} \\
\text { Conv. } \\
(\%)\end{array}$ & $\begin{array}{c}\text { Yield } \\
(\%)\end{array}$ \\
\hline $\mathbf{1}$ & MeOH 2a & 1 & 75 & 15 & 100 & 88 & 100 & 90 \\
\hline $\mathbf{2}$ & EtOH 2b & 2 & 78 & 18 & 100 & 91 & 100 & 91 \\
\hline $\mathbf{3}$ & $n$ BuOH 2c & 2 & 53 & 8 & 100 & 74 & 100 & 78 \\
\hline $\mathbf{4}$ & $i$ PrOH 2d & 24 & 23 & 1 & 100 & 40 & 100 & 29 \\
\hline $\mathbf{5}$ & $2-$ EtHxOH 2e & 24 & 49 & 9 & 100 & 44 & 100 & 87 \\
\hline $\mathbf{6}$ & TFE 2f & 24 & 100 & 88 & 100 & 72 & 100 & 67 \\
\hline $\mathbf{7}$ & Phenol 2g & 48 & 100 & 23 & 100 & 28 & 100 & 88 \\
\hline
\end{tabular}

Reaction conditions: 1.4:1 base:1 molar ratio, 15:1 molar ratio of alcohol 2 to epichlorohydrin (1), $65^{\circ} \mathrm{C}$. Conversions and yields were determined by GC.

A marked influence of the nature of the base was observed (table 2). Thus, $\mathrm{NaOH}$ or $\mathrm{KOH}$ provided high conversions of epichlorohydrin (1) in quite short times for linear, branched and aromatic alcohols (2a-e, $\mathbf{2 g}$ ), whereas the use of $\mathrm{LiOH}$ also led to complete conversion with the more acidic alcohols, phenol (2g) and TFE (2f), and also gave higher product yields with TFE.

As expected, the reactivity of alcohols $\mathbf{2}$ decreases with both chain length and branching. In the case of methanol (2a) (Table 2, entry 1), a $90 \%$ yield of $\mathbf{4 a}$ was obtained in $1 \mathrm{~h}$ using $\mathrm{KOH}$ or $\mathrm{NaOH}$. When lengthening the alkyl chain of the alcohol, for example when using EtOH $\mathbf{2 b}$ and $n \mathrm{BuOH} \mathbf{2 c}$ (Table 2, entries 2, 3), the maximum yield of the desired product 4 is maintained with respect to methanol but a reaction time of $2 \mathrm{~h}$ is required. When using branched alcohols, and hence less nucleophilic, such as isopropanol 2d or 2-ethylhexan-1-ol 2e (Table 2, entries 4, 5), reaction times of $24 \mathrm{~h}$ are required. As 
expected, more acidic, but less nucleophilic, alcohols $\mathbf{2 f}$ y $\mathbf{2 g}$ are also less reactive nevertheless high yields can also be reached but in longer time reaction.

Finally, the selectivity towards GDEs 4 was also studied. A reduction in the yields of diethers 4 can be attributed to competing dimerization and oligomerization processes, which generate different species. When formed, these oligomers can be detected by gas chromatography and identified by mass spectrometry/NMR spectroscopy (See supporting information).

Very high product selectivities are achieved for more reactive alcohols such as $\mathrm{MeOH}$ and $\mathrm{EtOH}$, whereas the values decrease slightly when using n-BuOH 2c, TFE 2f, $\mathrm{PhOH}$ $\mathbf{2 g}$ or 2-ethylhexan-1-ol $\mathbf{2 e}$. In the case of isopropanol $\mathbf{2 d}$, the presence of a less reactive secondary alcohol leads to only a $40 \%$ selectivity for $\mathbf{4 d}$.

All these data show that $\mathrm{NaOH}$ and $\mathrm{KOH}$ are the best bases for the reaction of epichlorhohydrin with alkyl alcohols. No significant differences are observed using both bases neither in yields nor in selectivities. It is worth mentioning the good results obtained with $\mathrm{LiOH}$ in the case of TFE. As mentioned, TFE is a more acidic alcohol, thus $\mathrm{LiOH}$ is basic enough to form the alkoxide and in this case the size of the cation plays an important role, thus the presence of lithium, a smaller cation, favors the reaction of trifluoroethoxyde with epichlorohydryn leading to an increase in product yield.

In order to prove the viability of this synthetic methodology, a scale up to 1 mol (120$316 \mathrm{~g}$ ) was performed for each alcohol using the optimal conditions. Final yields were maintained in all cases. The isolated yields of glyceryl diethers $4 \mathbf{a}-\mathbf{f}$ after vacuum distillation at $310^{-2}$ mbar depend strongly on the boiling point of the product (Table 3 ).

For diethers with a boiling point of $200^{\circ} \mathrm{C}$ or above, higher vacuum is needed in order to avoid high distillation temperatures (see product boiling points in table 7) and thus a loss of the product by side dimerization reactions. A proof of concept was carried out with product 4c. A synthesis at $20 \mathrm{~g}$ scale has been carried out and purification of the product 
was done using a kugelrohr distillation at $10^{3} \mathrm{mbar}$ and $90^{\circ} \mathrm{C}$. Thus, an improved yield of isolated product up to $60 \%$ was achieved.

Table 3. GC yields versus isolated yields for symmetric glyceryl diethers $\mathbf{4 a}-\mathbf{g}$

\begin{tabular}{cccccccc}
\hline \multicolumn{1}{c}{ Product } & $\mathbf{4 a}$ & $\mathbf{4 b}$ & $\mathbf{4 c}$ & $\mathbf{4 d}$ & $\mathbf{4 e}$ & $\mathbf{4 f}$ & $\mathbf{4 g}$ \\
\hline & {$[1.0 .1]$} & {$[2.0 .2]$} & {$[4.0 .4]$} & {$[3 \mathrm{i} .0 .3 \mathrm{i}]$} & {$\left[6_{2.0 .6}\right]$} & {$[3 \mathrm{~F} .0 .3 \mathrm{~F}]$} & {$[\mathrm{Ph} .0 . \mathrm{Ph}]^{\mathrm{b}}$} \\
\hline GC yield (\%) & 90 & 91 & 80 & 40 & 87 & 67 & 88 \\
Isolated yield (\%) & 85 & 72 & $47(60)^{\mathrm{a}}$ & 30 & 61 & 47 & 32 \\
\hline
\end{tabular}

Reaction conditions: 1.4:1 base: $\mathbf{1}$ molar ratio $(\mathrm{KOH}$ for $\mathbf{4 a}-\mathbf{c}$ and $\mathbf{4 e}-\mathbf{g}$, and $\mathrm{NaOH}$ for $\mathbf{4 d}$ ), 15:1 molar ratio of alcohol 2 to epichlorohydrin $(\mathbf{1}), 65^{\circ} \mathrm{C}$. Products were purified by vacuum distillation and a purity of $100 \%$ was determined for all products by HRMS a) distillation at $90^{\circ} \mathrm{C}$ and $10^{3}$ mbar. b) column chromatography was used for purification

\section{Screening of the reaction conditions for the synthesis of glycidyl ethers}

When carrying out the synthesis of glyceryl diethers 4 with the different bases, the formation of glycidyl ethers 3 was observed in the early stages of the reaction (Figure 1). This fact prompted us to fine-tune the reaction conditions in order to optimize the production of these glycidyl ether intermediates (3), which are very interesting and useful platform molecules derived from glycerol that can subsequently react with different nucleophiles for conversion, for example, into non-symmetric glycerol-derived diethers..$^{33}$ In this regard, screening of the reaction conditions was carried out for the synthesis of $\mathbf{3 a}$, optimizing the reaction temperature and concentration of alcohol 2a in order to provide the maximum amount of the glycidyl ether (Scheme 1). Equimolecular amounts of base were used in all cases.

The yields of glycidyl ether 3a for each reaction temperature were $53 \%$ in 10 min at $65{ }^{\circ} \mathrm{C}$, $54 \%$ in $30 \mathrm{~min}$ at $45{ }^{\circ} \mathrm{C}$ and $54 \%$ in $2 \mathrm{~h}$ at $25{ }^{\circ} \mathrm{C}$. Varying amounts of epichlorohydrin (1) and diether $4 \mathbf{a}$ were observed in all cases. As only differences in reaction time were observed, a 
temperature of $65{ }^{\circ} \mathrm{C}$ was chosen for subsequent reactions. The influence of reagent concentration appears to be decisive in order to avoid further transformation of 3a into $\mathbf{4 a}$. As such, four different molar ratios of methanol (2a) and epichlorohydrin (1), namely 40:1, 30:1, 15:1 and 7.5:1, were tested. As expected, the highest yields of 3a were obtained using higher dilutions (Table 4, entries 1 and 2). In a compromise between yield, selectivity and reaction time, a ratio of 30:1 seems to provide the best results.

Table 4. Yields of glycidyl methyl ether 3a at different reagent concentrations

\begin{tabular}{llll}
\hline Entry & 2a:1 ratio & Time (h) & Yield 3a (\%) \\
\hline $\mathbf{1}$ & $40: 1$ & 4 & 59 \\
$\mathbf{2}$ & $30: 1$ & 1.5 & 61 \\
$\mathbf{3}$ & $15: 1$ & 0.2 & 53 \\
$\mathbf{4}$ & $7.5: 1$ & 0.2 & 46 \\
\hline
\end{tabular}

Reaction conditions: $1: 1$ molar ratio of $\mathrm{KOH}$ to $1,65^{\circ} \mathrm{C}$.

The optimized reaction conditions were applied to the synthesis of different glycidyl ethers starting from 1 and previously selected alcohols 2a-g. Again, the results obtained with $\mathrm{LiOH}$ and $\mathrm{NaOH}$ are presented together with those obtained for $\mathrm{KOH}$. In all cases, $\mathrm{KOH}$ provided higher yields of $\mathbf{3}$ than $\mathrm{NaOH}$, which in turn gave higher yields than $\mathrm{LiOH}$ (Table 5).

Table 5. Epichlorohydrin (ECH) conversion, alkyl glycidyl ether $\mathbf{3}$ yield and selectivities (\%) for the reaction of ECH (1) and different alcohols 2 catalyzed by alkaline hydroxides ${ }^{a}$

\begin{tabular}{llcccccccccc}
\hline & & \multicolumn{3}{c}{ LiOH } & \multicolumn{3}{c}{ NaOH } & \multicolumn{3}{c}{ KOH } \\
\cline { 3 - 10 } Entry & Alcohol & $\begin{array}{c}\text { Time } \\
(\mathrm{h})\end{array}$ & $\begin{array}{c}\text { Conv. } \\
(\%)\end{array}$ & $\begin{array}{c}\text { Yield } \\
(\%)\end{array}$ & $\begin{array}{c}\text { Time } \\
(\mathrm{h})\end{array}$ & $\begin{array}{c}\text { Conv. } \\
(\%)\end{array}$ & $\begin{array}{c}\text { Yield } \\
(\%)\end{array}$ & $\begin{array}{c}\text { Time } \\
(\mathrm{h})\end{array}$ & $\begin{array}{c}\text { Conv. } \\
(\%)\end{array}$ & $\begin{array}{c}\text { Yield } \\
(\%)\end{array}$ \\
\hline $\mathbf{1}$ & $\mathrm{MeOH}$ & 0.75 & 80 & $\begin{array}{c}54 \\
(67)\end{array}$ & 1 & 85 & $\begin{array}{c}56 \\
(66)\end{array}$ & 1.5 & 90 & $\begin{array}{l}61 \\
(68)\end{array}$ \\
\hline
\end{tabular}




\begin{tabular}{|c|c|c|c|c|c|c|c|c|c|c|}
\hline 2 & $\mathrm{EtOH}$ & 1 & 83 & $\begin{array}{c}61 \\
(73)\end{array}$ & 1.5 & 92 & $\begin{array}{c}63 \\
(68)\end{array}$ & 0.5 & 87 & $\begin{array}{c}70 \\
(80)\end{array}$ \\
\hline 3 & $n \mathrm{BuOH}$ & 3 & 78 & $\begin{array}{c}51 \\
(65)\end{array}$ & 0.25 & 83 & $\begin{array}{c}59 \\
(71)\end{array}$ & 2 & 90 & $\begin{array}{c}65 \\
(72)\end{array}$ \\
\hline 4 & $i \mathrm{PrOH}$ & 96 & 70 & $\begin{array}{c}37 \\
(52)\end{array}$ & 1 & 87 & $\begin{array}{c}58 \\
(67)\end{array}$ & 1.5 & 86 & $\begin{array}{c}53 \\
(62)\end{array}$ \\
\hline 5 & 2-EtHxOH & 72 & 50 & $\begin{array}{c}35 \\
(70)\end{array}$ & 24 & 96 & $\begin{array}{c}50 \\
(52)\end{array}$ & 48 & 86 & $\begin{array}{c}67 \\
\text { (77) }\end{array}$ \\
\hline 6 & TFE & 6 & $68^{b}$ & $\begin{array}{c}39 \\
(57)\end{array}$ & 6 & 65 & $\begin{array}{c}44 \\
(67)\end{array}$ & 4 & 58 & $\begin{array}{c}54 \\
(93)\end{array}$ \\
\hline 7 & $\mathrm{PhOH}$ & 6 & $84^{\circ}$ & $\begin{array}{c}46 \\
(54)\end{array}$ & 24 & $100^{\circ}$ & $\begin{array}{c}55 \\
(55)\end{array}$ & 6 & $93^{\circ}$ & $\begin{array}{c}63 \\
\text { (67) }\end{array}$ \\
\hline
\end{tabular}

a Reaction conditions: 1:1 molar ratio of base to epichlorohydrin (1), $65{ }^{\circ} \mathrm{C}$ reaction temperature, 30:1 molar ratio of alcohol 2 to $\mathbf{1}$, at the glycidyl ether maximum yield.

' Formation of the corresponding 1-alkoxy-3-chloropropan-2-ol is observed.

-Values in brackets correspond to product selectivity.

Moderate yields were obtained in all cases. It should be noted that the glycidyl ether is always obtained together with epichlorohydrin (1) and glyceryl diethers 4 in different ratios depending both on the reactivity of the starting alcohol and the base. In order to obtain the pure glycidyl ethers, purification, mainly distillation, must be performed.

\section{Sustainability considerations regarding the synthetic methodology}

We have presented a methodology for the synthesis of symmetric glycidyl diethers involving the reaction of epichlorohydrin with several alcohols in the presence of $\mathrm{KOH}$ as base. From a sustainability point of view, the use of epichlorohydrin, which is considered to be a hazardous chemical, can be considered a serious drawback, although some green metrics show that the synthetic methodology discussed above may be competitive when compared to "similar" ones using glycerol as starting product.

We have taken the reaction of epichlorohydrin and methanol to form $\mathbf{4 a}$ as reference as this is the most commonly described process in the literature. This reaction is carried out at $65{ }^{\circ} \mathrm{C}$ and 
leads to total conversion of epichlorohydrin in $15 \mathrm{~min}$, with an isolated yield of $85 \%$ for 1,3 dimethoxy-2-propanol. The calculated atom economy (A.E.) is 0.67 , including the stoichiometric amount of $\mathrm{KOH}$ needed for the $\mathrm{SN}_{2}$ substitution reaction. The E Factor (EF) and stoichiometric factor $(\mathrm{SF})$, taking into account the recovery of the excess methanol by distillation, are 1.37 and 1, respectively. Other mass-based green metrics, such as RME (reaction mass efficiency), which is defined as mass of product/total mass of reactants, and MP (mass productivity), defined as mass of product/total mass including solvents, were also calculated. ${ }^{34}$ The values obtained for our process are 0.57 and 0.148 , respectively. Some of these parameters are represented in Figure 3 for a clearer comparison. The optimal process is the one in which all values are equal to 1 .

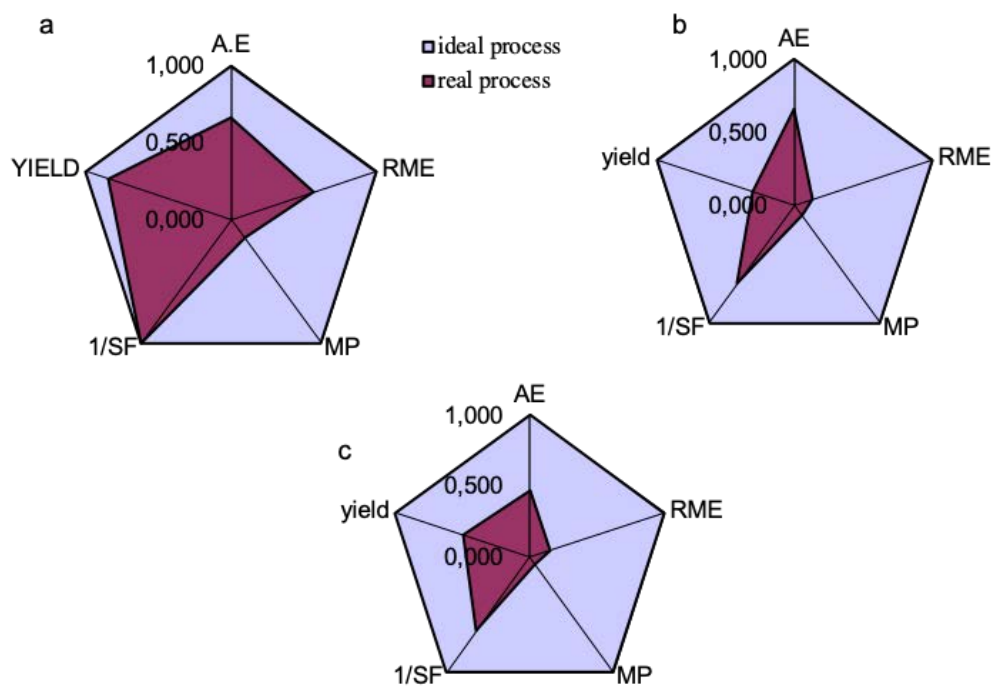

Figure 3. Green metrics for the synthesis of 4a. a) From epichlorohydrin (in this work); b) from glycerol and $\mathrm{TMAOH}^{35}$; ) from glycerol and dimethyl sulfate ${ }^{36}$ 
In light of these parameters, the weak points of our synthetic methodology are the AE and MP values. The moderate $\mathrm{AE}$ value is due to the use of stoichiometric amounts of base, which gives $\mathrm{KCl}$ as the only byproduct of the reaction. In the case of MP, the low value is due to work-up of the reaction in which, again, $\mathrm{KCl}$ is obtained as residue, as well as use of the alcohol, which acts as both reagent and solvent in the process, in a large excess. Although this is a drawback from a green metrics point of view, it is also an advantage as no additional solvent is used, thus facilitating purification of the product and enabling recovery of the solvent for subsequent reactions.

Various studies concerning the synthesis of ethers using glycerol as reagent have been published. In order to compare the sustainability of these processes with the results presented in this work, we have calculated the same green metrics for these reactions. In the work presented by Waggoner and Hatcher, ${ }^{35}$ glycerol is treated with tetramethylammonium hydroxide at $330{ }^{\circ} \mathrm{C}$ to give mixtures of mono-, di- and trimethyl glyceryl ethers. A 30\% yield of 1,3-dimethoxy-2propanol was reported. When using dimethyl sulfate as alkylating agent, ${ }^{36} \mathrm{NaOH}$ was used as base and chloroform as extraction solvent. In this case, a 50\% yield of 1,3-dimethoxy-2-propanol was obtained. As can be seen from Figure 3, all the green metrics parameters are much more unfavorable for these processes compared to the methodology described herein. Finally, some consideration about reagents toxicity can be done. In the case of the methodology herein presented, the use of epichlorohydrin can be considered as a drawback due to its toxicity, but the use of ECH in stoichiometric amounts and its total conversion minimizes the risk. In the case of the synthesis using methylating agents such as tetramethylammonium hydroxide and dimethyl sulfate both are also considered as toxic and are used in excess in respect to glycerol, that can be considered an additional drawback to the methodology. 
With regard to the remaining publications, most of which are patents, several key values are lacking from the description, thus making calculation of the green metrics impossible. Acid catalysts such as $\beta$-zeolite ${ }^{37}$, sulfuric acid $^{38}$ or Amberlyst $70^{29}$ have been used in the reaction of glycerol and methanol. However, reaction temperatures exceeded $130{ }^{\circ} \mathrm{C}$ in all cases. The production of mixtures of mono-, di- and triethers is always reported, with glyceryl triethers being the major products; the yield of 1,3-glyceryl diethers is not recorded (Table 6). In these cases, although the use of glycerol is more favorable from a green chemistry point of view, the use of much higher temperatures and the production of product mixtures with a very low selectivity for 1,3-glyceryl diethers can be considered serious drawbacks.

In summary, we can conclude that, despite the use of epichlorohydrin, the methodology described herein is a much more straightforward method for the synthesis of glyceryl-1,3diethers in high yield and selectivity, and with favorable green metrics.

Table 6. Comparison of synthetic methodologies for the synthesis of 1,3-dimethoxy-2-propanol (4a). ${ }^{a}$

\begin{tabular}{|c|c|c|c|c|c|c|}
\hline Reference & $\begin{array}{l}\text { Starting } \\
\text { material }\end{array}$ & Reagent/catalyst & solvent & $\begin{array}{l}\text { Reaction } \\
\text { conditions }\end{array}$ & Work-up & Yield of $\mathbf{4 a}$ \\
\hline This work & $\mathrm{ECH}$ & $\mathrm{MeOH} / \mathrm{KOH}$ & $\mathrm{MeOH}$ & $\begin{array}{l}65^{\circ} \mathrm{C} \\
1 \mathrm{~h}\end{array}$ & $\mathrm{HCl}$ & $85 \%$ \\
\hline $\begin{array}{l}\text { Waggoner et } \\
\text { al. } .^{35}\end{array}$ & glycerol & $\mathrm{TMAOH}^{\mathrm{a}}$ & $\mathrm{MeOH}$ & $\begin{array}{l}350^{\circ} \mathrm{C} \\
2 \mathrm{~min} .\end{array}$ & & $30 \%$ \\
\hline Chang et al. ${ }^{36}$ & glycerol & $\mathrm{Me}_{2} \mathrm{SO}_{4}$ & $\mathrm{H}_{2} \mathrm{O}$ & $\begin{array}{l}70^{\circ} \mathrm{C} \\
6 h\end{array}$ & $\mathrm{CHCl}_{3}$ & $50 \%$ \\
\hline Mota et al. ${ }^{37}$ & glycerol & $\begin{array}{l}\mathrm{MeOH} / \beta \text { zeolite } \\
(20 \% \mathrm{w} / \mathrm{w})\end{array}$ & $\mathrm{MeOH}$ & $\begin{array}{l}150^{\circ} \mathrm{C} \\
5 \mathrm{~h}\end{array}$ & -- & $\begin{array}{l}\text { Mixtures } \\
\text { of ethers }\end{array}$ \\
\hline
\end{tabular}




\begin{tabular}{|c|c|c|c|c|}
\hline $\begin{array}{l}\text { Dos Santos et glycerol } \\
\text { al. }{ }^{38}\end{array}$ & $\mathrm{H}_{2} \mathrm{SO}_{4}$ or $\mathrm{HX}$ & $\mathrm{MeOH}$ & $\begin{array}{lll}150 & { }^{\circ} \mathrm{C} & \mathrm{AC}^{\mathrm{b}} \\
1.5 \mathrm{~h} & & \end{array}$ & $\begin{array}{l}\text { Mixtures } \\
\text { of ethers }\end{array}$ \\
\hline Chang et al..$^{29}$ glycerol & $\begin{array}{l}\text { 1) } \mathrm{MeOH} / \mathrm{A} 70 \\
\text { 2) } \mathrm{Me}_{2} \mathrm{SO}_{4} / \mathrm{NaOH}\end{array}$ & $\begin{array}{l}\text { 1) } \mathrm{MeOH} \\
\text { 2) } \mathrm{H}_{2} \mathrm{O}\end{array}$ & $\begin{array}{l}\text { 1) } 150{ }^{\circ} \mathrm{C} \\
\text { 24h } \\
\text { 2) } 70{ }^{\circ} \mathrm{C} \\
1 \text { day }\end{array}$ & $\begin{array}{l}\text { Mixtures } \\
\text { of ethers }\end{array}$ \\
\hline
\end{tabular}

"TMAOH: Tetramethylammonium hydroxide. ${ }^{\circ} \mathrm{AC}:$ Activated Carbon

\section{Physicochemical properties of symmetric glyceryl diethers}

The physicochemical properties of this family of ethers are closely related to their ability to form hydrogen bonds, therefore the shielding and dilution of the $\mathrm{OH}$ group when the alkyl chains of the ether groups are modified should allow these properties to be tuned.

The most interesting physicochemical properties as regards use of the synthesized symmetric glyceryl diethers 4 [R.0.R] as solvents were measured in the milder temperature range of 25-70 ${ }^{\circ} \mathrm{C}$, and the experimental data were fitted to linear equations (see Supporting Information).

Some of the properties reported herein, such as density and refractivity, have been reported previously for some of the ethers, but always at a fixed temperature of 20 or $25^{\circ} \mathrm{C} . .^{1539}$ It should be noted that, except for the boiling point, the physicochemical properties of $4 \mathbf{e}\left[6_{2} .0 .6_{2}\right],[8.0 .8]$, [5.0.5] and $\mathbf{4 g}[\mathrm{Ph} .0 . \mathrm{Ph}]$ are reported here for the first time. In the case of viscosity, only the values for $\mathbf{4 c}[4.0 .4]$ and $\mathbf{4 f}[3 \mathrm{~F} .0 .3 \mathrm{~F}]$ at $20^{\circ} \mathrm{C}$ have been reported previously by our group..$^{\text {s }}$

Density (@). Density is an essential property of solvents for many chemical, industrial and engineering applications. The density values of these solvents at $25{ }^{\circ} \mathrm{C}$ range between 0.88 and $1.01 \mathrm{~g} \cdot \mathrm{cm}^{-3}$ (with the expected exception of fluorinated $4 \mathbf{f}[3 \mathrm{~F} .0 .3 \mathrm{~F}], 1.39 \mathrm{~g} \cdot \mathrm{cm}^{-3}$ ) and are therefore comparable to those of other conventional organic solvents $\left(0.75-1.00 \mathrm{~g} \cdot \mathrm{cm}^{-3}\right.$; (Figure 4). These density values are similar to those for glyceryl monoethers [R.0.0] $\left(0.96-1.36 \mathrm{~g} \cdot \mathrm{cm}^{-3}\right)$ 
and glyceryl triethers [R.R.R] $\left(0.85-0.95 \mathrm{~g} \cdot \mathrm{cm}^{-3}\right)$, and are lower than that pure glycerol $(1.26$ $\left.\mathrm{g} \cdot \mathrm{cm}^{-3}\right)$, glyceline $\left(1.19 \mathrm{~g} \cdot \mathrm{cm}^{-3}\right)$, glycerol monoethers DES $\left(1.05-1.30 \mathrm{~g} \cdot \mathrm{cm}^{-3}\right)$ and the majority of ILs (ionic liquids) $\left(1.21-1.45 \mathrm{~g} \cdot \mathrm{cm}^{-3}\right) .^{15,17}$ As is usually the case for organic liquids, density decreases with increasing temperature as a result of thermal expansion. However, this decrease is almost negligible in this case as it is counteracted by opposing effects (see Supporting Information), namely hydrogen bond breakage, which leads to a contraction in the liquid, and an increase in the free volume, which leads to an expansion in the liquid. Branching leads to a decrease in density (cf. $4 \mathbf{d}$ [3i.0.3i] vs. [3.0.3], and $4 \mathbf{e}\left[6_{2} .0 .6_{2}\right]$ vs. [8.0.8]). Finally, the fluorinated diether $4 \mathbf{f}[3 \mathrm{~F} .0 .3 \mathrm{~F}]$ displays the highest density due to the high atomic mass of fluorine atoms (Figure 4).

Sound propagation speed $(\boldsymbol{u})$. This property is inversely related to density, as can be seen from the basic thermodynamic relationship.

$$
\kappa_{S}=\frac{1}{\rho u^{2}}
$$

where $\kappa_{S}$ is the isentropic compressibility coefficient.

As such, trends in $u$ are parallel but opposite to those in density (see Supporting Information). For 4 [R.0.R], $u$ values at $25^{\circ} \mathrm{C}$ range from 1040 to $1388 \mathrm{~m} \cdot \mathrm{s}^{-1}$ and are therefore similar to those for conventional solvents such as methanol $\left(1103 \mathrm{~m} \cdot \mathrm{s}^{-1}\right)$, acetone $\left(1170 \mathrm{~m} \cdot \mathrm{s}^{-1}\right)$, toluene (1306 $\left.\mathrm{m} \cdot \mathrm{s}^{-1}\right)$ or water $\left(1493 \mathrm{~m} \cdot \mathrm{s}^{-1}\right) \cdot{ }^{17}$

Molar Volume $\left(\boldsymbol{V}_{m}\right)$. This property is related to the free volume of a molecule at a given temperature and, like density, presents interesting correlations with other properties such as viscosity. Molar volumes were calculated using the semi-empirical equation 3, where $M$ is the molar mass in $\mathrm{g} \cdot \mathrm{mol}^{-1}$ and $\varrho$ the solvent density $\left(\mathrm{g} \cdot \mathrm{cm}^{-3}\right)$ : 


$$
V_{m}=\frac{M\left(g \cdot \mathrm{mol}^{-1}\right)}{\rho\left(\mathrm{g} \cdot \mathrm{cm}^{-3}\right)}
$$

The molar volums of these diethers at $25^{\circ} \mathrm{C}$ vary widely between 120 and $360 \mathrm{~cm}^{3} \cdot \mathrm{mol}^{-{ }^{-1}}$ and are intermediate between those for glyceryl mono- $\left(95-180 \mathrm{~cm}^{3} \cdot \mathrm{mol}^{-1}\right)$ and triethers $(150-300$ $\left.\mathrm{cm}^{3} \cdot \mathrm{mol}^{-1}\right){ }^{17}$ By definition, molar volume is inversely proportional to density, therefore trends with chain length, branching and temperature are the opposite (see Supporting Information).

Solvent Polarity. The polarity can be determined using both physical and chemical methods. We determined the dielectric permittivity and dipole moment as physical polarity parameters. The dielectric permittivity $(\varepsilon)$ of these solvents shows values (3-14 at room temp.) lower than those for glyceryl monoethers (8-25) and other alcohols (18-40) due to the higher symmetry of the molecule. ${ }^{17}$ As the alkyl chain lengthens, the polarity of these liquids decreases. Although branching effect has only a minimal effect on polarity, fluorination markedly increases permittivity (from 11 to 14 ). The dipole moments $(\mu)$, as calculated from experimental $\varepsilon, n_{b}$ and $\varrho$ values using Onsager's equation (1), show similar polarity trends as the permittivities, with values ranging between 2.0 and $3.1 \mathrm{D}(4.0 \mathrm{D}$ for $\mathbf{4 f}[3 \mathrm{~F} .0 .3 \mathrm{~F}])$, which are slightly higher than those for conventional solvents (1.3-1.8 D) but lower than those for glycerol monoethers (3.04.4 D). ${ }^{17}$

Refractive index $\left(\boldsymbol{n}_{D}\right)$. The refractivity of a molecule is a well-known estimator of its polarizability, and it has also been used in organic chemistry as a purity indicator. [R.0.R] 4 diethers present very similar refractivity values in all cases (between 1.41 and 1.45 at room temp.), with the exception of $\mathbf{4 f}[3 \mathrm{~F} .0 .3 \mathrm{~F}]$ (1.35). These values are in the range of those for conventional solvents (1.32-1.50) and glycerol (1.47), and decrease slightly with temperature. Longer alkyl chains lead to higher refractivities due to the correlation between the polarizability and the strength of chain interactions. In contrast, the high electronegativity of fluorine atoms 
markedly reduces the polarizability of $\mathbf{4 f}$ [3F.0.3F]. Finally, both branched $\mathbf{4 d}$ [3i.0.3i] and $\mathbf{4 e}$ [6.0.6. $\left.6_{2}\right]$ solvents present lower $n_{D}$ values than their linear counterparts.

Molar refractivity $\left(\boldsymbol{R}_{m}\right)$. This polarizability parameter was calculated using the Lorentz equation (4) from $n_{b}$ and molar volume values $\left(V_{m}\right)$. The molar refractivities of glyceryl diethers are in the range $30-100 \mathrm{~cm}^{3} \cdot \mathrm{mol}^{-1}$, and are thus higher than for most conventional solvents.

$$
R_{m}=\frac{n_{D}^{2}-1}{n_{D}^{2}+2} \cdot V_{m}
$$

Viscosity $(\boldsymbol{\eta})$. Liquid viscosity is an important physical property used in the design of fluidtransport processes. As such, flow times were measured at $25^{\circ} \mathrm{C}$ and kinematic viscosities were calculated after appropriate calibration of the viscometers. The viscosities of glyceryl 4 [R.0.R] diethers are much lower than those for glyceryl [R.0.0] monoethers, ${ }^{17}$ therefore their decrease with temperature is minimal (see Supporting Information). Dynamic viscosities were calculated from kinematic viscosities and densities according to equation 5.

$$
\eta=\nu \cdot \rho
$$

These solvents present very interesting fluency properties. Thus, their viscosities are in the range $3-17 \mathrm{cP}$ at $25^{\circ} \mathrm{C}$, much lower than those for glycerol (1200 cP), glycerol-derived DES $(130-550 \mathrm{cP})$ and glycerol-derived monoethers $(35-110 \mathrm{cP})$. This is due to the lower number of interactions present in diethers as they are less able to form hydrogen bonds. It should also be noted that these solvents have similar viscosities to conventional ones $(0.2-4 \mathrm{cP})$. This is important as it can lead to a reduction in energy and operating costs. In addition, longer ether chains lead to higher viscosities, with an exponential growth from 3.0 4a [1.0.1] to $3.3 \mathbf{4 b}$ [2.0.2], 5.6 4c [4.0.4], 9.5 4e [6.0.6] and $17.3 \mathrm{cP}$ [8.0.8] being observed (Figure 4). Branched diethers exhibit a marked viscosity decrease of close to $20 \%$ compared with the linear 
compounds. Finally, the fluorinated solvent $\mathbf{4 f}[3 \mathrm{~F} .0 .3 \mathrm{~F}]$ is three times more viscous than its nonfluorinated analog $\mathbf{4 b}$ [2.0.2] due to hydrogen-bond formation.

Surface tension $(\gamma)$. Surface tension can be considered to be a measure of the force acting on the boundary surface between a liquid phase and a gas (air) phase. As such, an understanding of surface tension is essential in order to be able to understand boiling and condensation processes, as well as the behavior shown by emulsions, foams, etc., which are common materials that can be formed when organic solvents pass into the environment. The range of surface tension values of the glyceryl 4 [R.0.R] diethers is $23.1-30.7 \mathrm{mN} \cdot \mathrm{m}^{-1}$ at room temperature (Figure 5). Interestingly, these values are not very different from those for glyceryl [R.0.0] monoethers (25$40 \mathrm{mN} \cdot \mathrm{m}^{-1}$ ) and even for conventional solvents such as common alcohols, such as methanol $\left(23.8 \mathrm{mN} \cdot \mathrm{m}^{-1}\right)$, acetone $\left(24.9 \mathrm{mN} \cdot \mathrm{m}^{-1}\right)$, aromatic solvents $\left(29.1 \mathrm{mN} \cdot \mathrm{m}^{-1}\right.$ for toluene) or halogenated solvents $\left(29.5 \mathrm{mN} \cdot \mathrm{m}^{-1}\right.$ for $\left.\mathrm{DCM}\right) .{ }^{17}$ Although higher surface tensions are found for short alkyl chain ethers, the decrease with chain length is not linear. Short chain alkyl ethers show the highest surface tensions, subsequently decreasing from $\mathbf{4 a}$ [1.0.1] to $\mathbf{4 c}$ [4.0.4], which can be explained by the dilution effect of the $\mathrm{OH}$ group. A slight increase with length of the ether group chain is then observed on going from [5.0.5] to [8.0.8], with this increase probably being associated with an increase in the interactions between aliphatic chains. Branching and fluorination effects lead to a decrease in surface tension (about $10 \%$ with respect to the linear compounds; Figure 5a).

Boiling point. The boiling points for 4 [R.0.R] were determined in order to determine their volatility. Table 7 shows that longer alkyl chains result in a decrease in volatility. Branched ethers, in turn, exhibit fewer interactions, thus lowering their boiling points, with the opposite 
trend being found for $[3 \mathrm{~F} \cdot 0.3 \mathrm{~F}]$. All these solvents have a very low volatility, thus reducing working risks.

Table 7. Boiling points of the [R.0.R] solvents synthesized

\begin{tabular}{ccccc}
\hline $\mathbf{4 a}[1.0 .1]$ & $\mathbf{4 b}[2.0 .2]$ & {$[3.0 .3]$} & $\mathbf{4 c}[4.0 .4]$ & {$[5.0 .5]$} \\
\hline $170{ }^{\circ} \mathrm{C}$ & $188^{\circ} \mathrm{C}$ & $219{ }^{\circ} \mathrm{C}$ & $248{ }^{\circ} \mathrm{C}$ & $285^{\circ} \mathrm{C}$ \\
\hline$[6.0 .6]$ & $\mathbf{4 f}[3 \mathrm{~F} .0 .3 \mathrm{~F}]$ & $\mathbf{4 d}[3 \mathrm{i} .0 .3 \mathrm{i}]$ & {$[8.0 .8]$} & $\mathbf{4 e}\left[6_{2} .0 .6_{2}\right]$ \\
\hline $316^{\circ} \mathrm{C}$ & $197{ }^{\circ} \mathrm{C}$ & $202{ }^{\circ} \mathrm{C}$ & $344{ }^{\circ} \mathrm{C}$ & $334{ }^{\circ} \mathrm{C}$ \\
\hline
\end{tabular}

In order to gain a better view of the most important physicochemical properties measured for glyceryl diethers, two-dimensional graphs of density, surface tension and boiling point vs. dynamic viscosity were plotted. Values for similar conventional solvents have been added for comparison.

The following abbreviations for conventional solvents are used in these plots for the sake of clarity:

$\begin{array}{llll}\text { MeOH } & \text { Methanol } & \text { EGMME } & \text { Ethylene glycol monomethyl ether } \\ \text { BuOH } & \text { 1-Butanol } & \text { EGDME } & \text { Ethylene glycol dimethyl ether } \\ \text { HxOH } & \text { 1-Hexanol } & \text { DEGMME } & \text { Diethylene glycol monomethyl ether } \\ \text { OctOH } & \text { 1-Octanol } & \text { DEGDME } & \text { Diethylene glycol dimethyl ether } \\ \text { DecOH } & \text { 1-Decanol } & \text { SK } & \text { Solketal } \\ \text { TFE } & \text { Trifluoroethanol } & \text { W } & \text { Water }\end{array}$

Figures $4 \mathrm{a}, 5 \mathrm{a}$ and $6 \mathrm{a}$ show the trends in 4 [R.0.R] properties discussed previously. These 2D graphs are very useful when choosing a solvent for a specific application. For example, Figure $5 \mathrm{~b}$ shows the wetting ability of the solvents, which is essential for extraction processes. In this case, compounds $\mathbf{4 a}[1.0 .1]$ and $\mathbf{4 b}$ [2.0.2] seem to be good candidates for replacing DEGMME, which has an intermediate wetting ability. Figure $6 \mathrm{~b}$, in which boiling point is plotted against 
dynamic viscosity, may be useful for choosing additives for cooling liquids, which should have a low viscosity and high boiling point. In this case, glyceryl diethers from $\mathbf{4 a}$ [1.0.1] to $\mathbf{4 b}$ [4.0.4] can be considered to be good candidates for replacing DEGDME and DEGMME.

Finally, these plots show that these glyceryl diethers are in the region corresponding to hydrogen bonding and aprotic polar solvents, where linear alcohols and diols coexist with ethers such as glymes (EGDME, DEGMME, etc.).
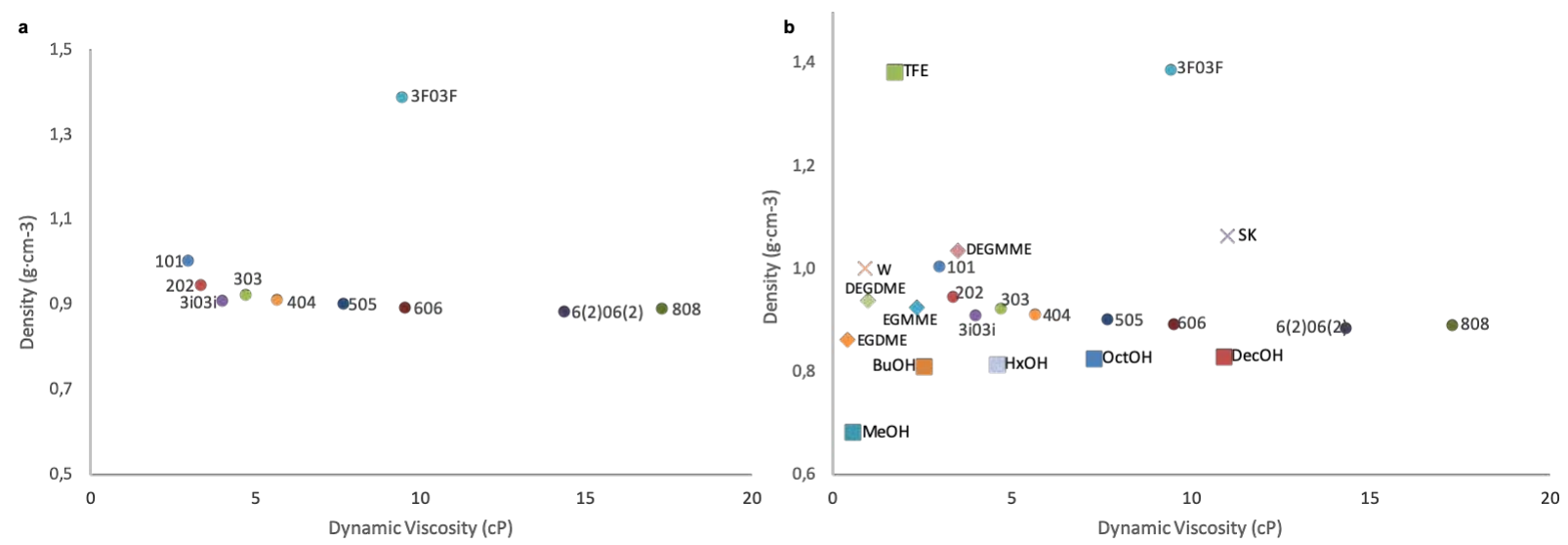

Figure 4. a) Plot of density vs. dynamic viscosity for glyceryl diethers 4 [R.0.R]; b) glyceryl diethers vs. some conventional solvents at $25^{\circ} \mathrm{C}$ 

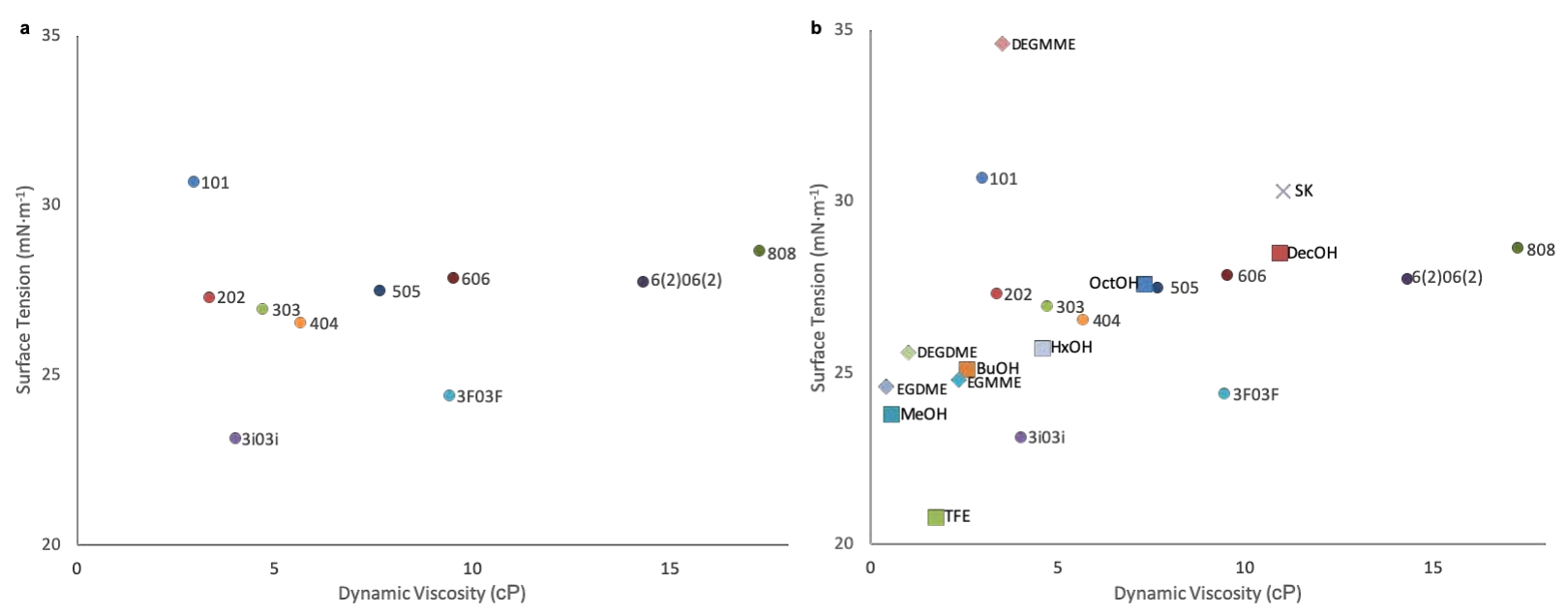

Figure 5. a) Plot of surface tension vs. dynamic viscosity for glyceryl diethers 4 [R.0.R]; b) glyceryl diethers vs. some conventional solvents at $25^{\circ} \mathrm{C}$
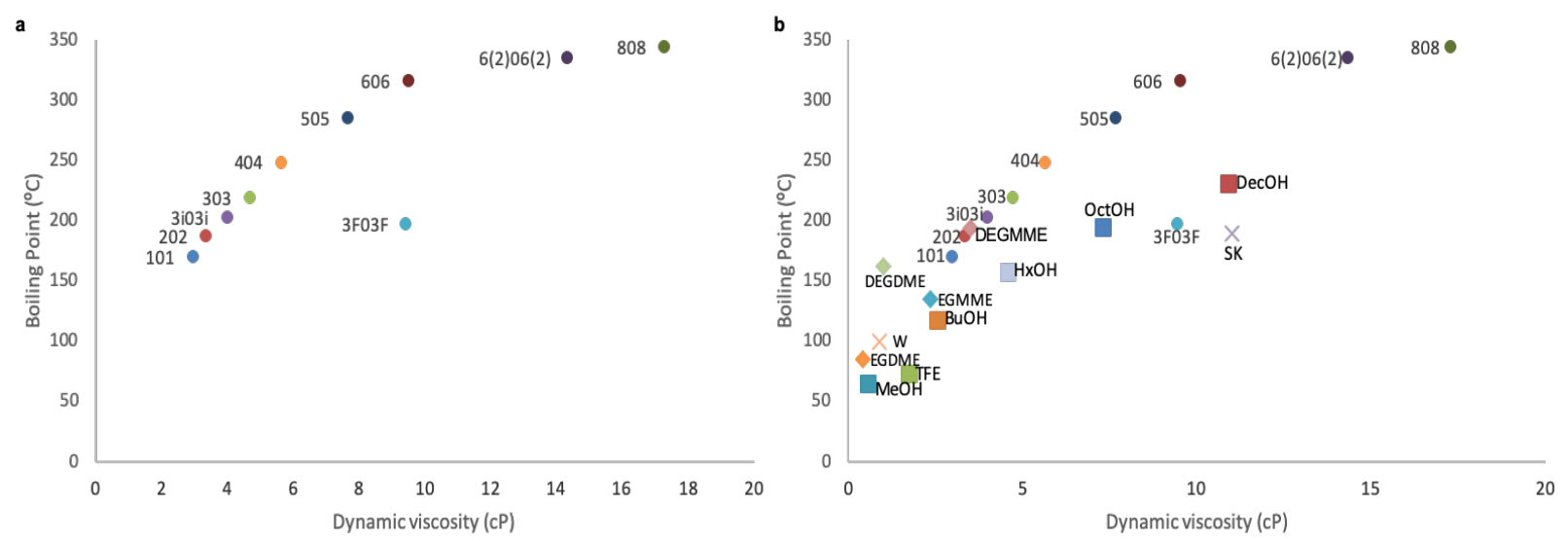

Figure 6. a) Plot of boiling point vs. dynamic viscosity for glyceryl diethers 4 [R.0.R]; b) glyceryl diethers vs. some conventional solvents at $25^{\circ} \mathrm{C}$

\section{CONCLUSIONS}

A systematic, alternative and efficient methodology for the synthesis of symmetric glycerol diethers, starting from epichlorohydrin, has been optimized using a range of alcohols with different structures and features. No excess epichlorohydrin is required and inexpensive alkaline hydroxides can be used to improve the sustainability of the process. This synthetic methodology 
avoids the use of co-solvents and uses milder reaction conditions and moderate reaction times. High yields of the desired product have been achieved, although the final selectivity of the reaction depends strongly on the alcohol used. In general, the best results are obtained with $\mathrm{KOH}$, with the exception of $\mathrm{NaOH}$ for branched alcohols and $\mathrm{LiOH}$ for more acidic ones. In this case, only $\mathrm{KCl}$ is obtained as byproduct.

An attempt to adapt this synthetic methodology to the synthesis of glycidyl ethers has also been made, with moderate yields of these platform molecules being achieved.

The new symmetric glycerol diethers synthesized have been fully characterized, and several of their essential physicochemical properties, such as density, molar volume, polarity, refractive index, viscosity, surface tension and volatility, have been measured, in most cases within the temperature range $25-70{ }^{\circ} \mathrm{C}$. The values obtained highlight the versatility of these molecules and show that the properties of the solvent can be modified simply by varying the substitution pattern. A comparison of these properties with those for similar, non-renewable solvents highlights the possibility of using glyceryl diethers as a green alternative, with some of these solvents appearing to be highly suitable for two common uses, namely reaction and extraction media.

\section{ASSOCIATED CONTENT}

\section{Supporting Information}

The supporting information contains the products characterization and description, the diagram of physicochemical properties vs temperature and physicochemical adjust parameters.

\section{AUTHOR INFORMATION}

\section{Corresponding Author}

Elísabet Pires. E-mail: epires@unizar.es 
ORCID 0000-0002-2676-8814

\section{Author Contributions}

The manuscript was written jointly by all authors, and all authors have given approval to the final version of the manuscript.

\section{ACKNOWLEDGMENTS}

Financial support from Ministerio de Ciencia, Innovación y Universidades (project RTI2018093431-B-I00) and the Gobierno de Aragón (Group E37_17R) co-funded by FEDER 2014-2020 "Construyendo Europa desde Aragón" is acknowledged. A. L-D. thanks the MECD for a FPU grant (FPU14/04338). The authors thank Dr. Carlos Lafuente for allowing them to use the surface tensiometer and for helpful advice.

\section{REFERENCES}

(1) Anastas, P. T.; Warner, J. C. Green Chemistry: Theory and Practice; Oxford University Press, 1998.

(2) Biermann, U.; Bornscheuer, U.; Meier, M. A. R.; Metzger, J. O.; Schaefer, H. J. Oils and Fats as Renewable Raw Materials in Chemistry. Angew. Chem.-Int. Edit. 2011, 50 (17), 38543871. doi:10.1002/anie.201002767.

(3) Gallezot, P. Conversion of Biomass to Selected Chemical Products. Chem. Soc. Rev. 2012, 41 (4), 1538-1558. doi:10.1039/C1CS15147A.

(4) Metzger, J. O. Fats and Oils as Renewable Feedstock for Chemistry. European Journal of Lipid Science and Technology 2009, 111 (9), 865-876. doi: 10.1002/ejlt.200900130.

(5) Quispe, C. A. G.; Coronado, C. J. R.; Carvalho Jr., J. A. Glycerol: Production, Consumption, Prices, Characterization and New Trends in Combustion. Renewable and Sustainable Energy Reviews 2013, 27, 475-493. https://doi.org/10.1016/j.rser.2013.06.017.

(6) García, J. I.; García-Marín, H.; Pires, E. Glycerol Based Solvents: Synthesis, Properties and Applications. Green Chem. 2014, 16 (3), 1007-1033. doi:10.1039/C3GC41857J.

(7) Díaz-Álvarez, A. E.; Francos, J.; Lastra-Barreira, B.; Crochet, P.; Cadierno, V. Glycerol and Derived Solvents: New Sustainable Reaction Media for Organic Synthesis. Chem. Commun. 2011, 47 (22), 6208-6227. doi:10.1039/C1CC10620A.

(8) Garcia-Alvarez, R.; Crochet, P.; Cadierno, V. Metal-Catalyzed Amide Bond Forming Reactions in an Environmentally Friendly Aqueous Medium: Nitrile Hydrations and Beyond. 
Green Chem. 2013, 15 (1), 46-66. doi:10.1039/c2gc36534k.

(9) Gu, Y.; Jerome, F. Glycerol as a Sustainable Solvent for Green Chemistry. Green Chem. 2010, 12 (7), 1127-1138. doi:10.1039/c001628d.

(10) Wolfson, A.; Snezhko, A.; Meyouhas, T.; Tavor, D. Glycerol Derivatives as Green Reaction Mediums. Green Chem. Lett. Rev. 2012, 5 (1), 7-12. doi:10.1080/17518253.2011.572298.

(11) Behr, A.; Eilting, J.; Irawadi, K.; Leschinski, J.; Lindner, F. Improved Utilisation of Renewable Resources: New Important Derivatives of Glycerol. Green Chem. 2008, 10 (1), 1330. doi:10.1039/B710561D.

(12) García, J. I.; Pires, E.; Aldea, L.; Lomba, L.; Perales, E.; Giner, B. Ecotoxicity Studies of Glycerol Ethers in Vibrio Fischeri: Checking the Environmental Impact of Glycerol-Derived Solvents. Green Chem. 2015, 17 (8), 4326-4333. doi:10.1039/C5GC00857C.

(13) Perales, E.; García, J. I.; Pires, E.; Aldea, L.; Lomba, L.; Giner, B. Ecotoxicity and QSAR Studies of Glycerol Ethers in Daphnia Magna. Chemosphere 2017, 183, 277-285. doi:10.1016/j.chemosphere.2017.05.107.

(14) Perales, E.; García, C. B.; Lomba, L.; García, J. I.; Pires, E.; Sancho, M. C.; Navarro, E.; Giner, B. Comparative Ecotoxicity Study of Glycerol-Biobased Solvents. Environmental Chemistry 2017, 14 (6), 370. doi:10.1071/EN17082.

(15) Garcia, J. I.; Garcia-Marin, H.; Mayoral, J. A.; Perez, P. Green Solvents from Glycerol. Synthesis and Physico-Chemical Properties of Alkyl Glycerol Ethers. Green Chemistry 2010, 12 (3), 426-434. doi:10.1039/b923631g.

(16) Garcia, J. I.; Garcia-Marin, H.; Mayoral, J. A.; Perez, P. Quantitative Structure-Property Relationships Prediction of Some Physico-Chemical Properties of Glycerol Based Solvents. Green Chem. 2013, 15 (8), 2283-2293. doi:10.1039/c3gc40694f.

(17) Leal-Duaso, A.; Pérez, P.; Mayoral, J. A.; Pires, E.; García, J. I. Glycerol as a Source of Designer Solvents: Physicochemical Properties of Low Melting Mixtures Containing Glycerol Ethers and Ammonium Salts. Phys. Chem. Chem. Phys. 2017, 19 (41), 28302-28312. doi:10.1039/C7CP04987K.

(18) Moity, L.; Durand, M.; Benazzouz, A.; Pierlot, C.; Molinier, V.; Aubry, J.-M. Panorama of Sustainable Solvents Using the COSMO-RS Approach. Green Chem. 2012, 14 (4), 11321145. doi:10.1039/C2GC16515E.

(19) Moity, L.; Shi, Y.; Molinier, V.; Dayoub, W.; Lemaire, M.; Aubry, J.-M. Hydrotropic Properties of Alkyl and Aryl Glycerol Monoethers. J. Phys. Chem. B 2013, 117 (31), 9262-9272. doi:10.1021/jp403347u.

(20) Sutter, M.; Silva, E. D.; Duguet, N.; Raoul, Y.; Métay, E.; Lemaire, M. Glycerol Ether Synthesis: A Bench Test for Green Chemistry Concepts and Technologies. Chemical Reviews 2015, 115 (16), 8609-8651. doi:10.1021/cr5004002. 
(21) Gu, Y.; Azzouzi, A.; Pouilloux, Y.; Jerome, F.; Barrault, J. Heterogeneously Catalyzed Etherification of Glycerol: New Pathways for Transformation of Glycerol to More Valuable Chemicals. Green Chem. 2008, 10 (2), 164-167. doi.:10.1039/b715802e.

(22) Gaudin, P.; Jacquot, R.; Marion, P.; Pouilloux, Y.; Jerome, F. Acid-Catalyzed Etherification of Glycerol with Long-Alkyl-Chain Alcohols. ChemSusChem 2011, 4 (6), 719 722. doi:10.1002/cssc.201100129.

(23) Liu, F.; Vigier, K. D. O.; Pera-Titus, M.; Pouilloux, Y.; Clacens, J.-M.; Decampo, F.; Jérôme, F. Catalytic Etherification of Glycerol with Short Chain Alkyl Alcohols in the Presence of Lewis Acids. Green Chem. 2013, 15 (4), 901-909. doi:10.1039/C3GC36944G.

(24) Leal-Duaso, A.; Caballero, M.; Urriolabeitia, A.; Mayoral, J. A.; García, J. I.; Pires, E. Synthesis of 3-Alkoxypropan-1,2-Diols from Glycidol: Experimental and Theoretical Studies for the Optimization of the Synthesis of Glycerol Derived Solvents. Green Chem. 2017, 19 (17), 4176-4185. doi:10.1039/C7GC01583F.

(25) Ricciardi, M.; Passarini, F.; Vassura, I.; Proto, A.; Capacchione, C.; Cucciniello, R.; Cespi, D. Glycidol, a Valuable Substrate for the Synthesis of Monoalkyl Glyceryl Ethers: A Simplified Life Cycle Approach. ChemSusChem 2017, 10 (10), 2291-2300. doi: 10.1002/cssc.201700525.

(26) Cucciniello, R.; Ricciardi, M.; Vitiello, R.; Di Serio, M.; Proto, A.; Capacchione, C. Synthesis of Monoalkyl Glyceryl Ethers by Ring Opening of Glycidol with Alcohols in the Presence of Lewis Acids. ChemSusChem 2016, 9 (23), 3272-3275. doi: 10.1002/cssc. 201600989 .

(27) Gilbeau, P.; Krafft, P. Process for Manufacturing Epichlorohydrin. US20100032617A1, February 11, 2010.

(28) Onsager, L. Electric Moments of Molecules in Liquids. J. Am. Chem. Soc. 1936, 58, 1486-1493. doi:10.1021/ja01299a050.

(29) Chang, J.-S.; Ling, T.-R.; Chou, T.-C.; Chou, L. C.-S. Oxygenate Additive for Internal Combustion Engine Fuel, Fuel Composition Comprising the Same and Improved Process for Producing Highly Methylated Glycerol Ethers. US2013133245 (A1), May 30, 2013.

(30) Hernaiz, M. J.; Alcantara, A. R.; Garcia, J. I.; Sinisterra, J. V. Applied Biotransformations in Green Solvents. Chemistry-a European Journal 2010, 16 (31), 94229437. doi:10.1002/chem.201000798.

(31) de Torres, M.; Jimenez-Oses, G.; Antonio Mayoral, J.; Pires, E.; Maria Blanco, R.; Fernandez, O. Evaluation of Several Catalytic Systems for the Epoxidation of Methyl Oleate Using $\mathrm{H} 2 \mathrm{O} 2$ as Oxidant. Catalysis Today 2012, 195 (1), 76-82. doi: 10.1016/j.cattod.2012.05.005.

(32) Garcia-Marin, H.; van der Toorn, J. C.; Mayoral, J. A.; Garcia, J. I.; Arends, I. W. C. E. Glycerol-Based Solvents as Green Reaction Media in Epoxidations with Hydrogen Peroxide Catalysed by Bis[3,5-Bis(Trifluoromethyl)-Diphenyl] Diselenide. Green Chemistry 2009, 11 
(10), 1605-1609. doi: 10.1039/b913052g.

(33) Lebeuf, R.; Illous, E.; Dussenne, C.; Molinier, V.; Silva, E. D.; Lemaire, M.; Aubry, J.M. Solvo-Surfactant Properties of Dialkyl Glycerol Ethers: Application as Eco-Friendly Extractants of Plant Material through a Novel Hydrotropic Cloud Point Extraction (HCPE) Process. ACS Sustainable Chemistry \& Engineering 2016, 4 (9), 4815-4823. doi: 10.1021/acssuschemeng.6b01101.

(34) Sheldon, R. A. Metrics of Green Chemistry and Sustainability: Past, Present, and Future. ACS Sustainable Chem. Eng. 2018, 6 (1), 32-48. doi.org/10.1021/acssuschemeng.7b03505.

(35) Waggoner, D. C.; Hatcher, P. G. Thermally Assisted Methylation of Glycerol by Tetramethylammonium Hydroxide Thermochemolysis. Journal of Analytical and Applied Pyrolysis 2016, 122, 289-293. doi.org/10.1016/j.jaap.2016.09.014.

(36) Chang, J.-S.; Lee, Y.-D.; Chou, L. C.-S.; Ling, T.-R.; Chou, T.-C. Methylation of Glycerol with Dimethyl Sulfate To Produce a New Oxygenate Additive for Diesels. Ind. Eng. Chem. Res. 2012, 51 (2), 655-661. doi.org/10.1021/ie201612t.

(37) Peres Pinto, B.; Mota, C.J.A., C. J. A.; Gonçalves, V.L.C. Processos de Obtenção de Éteres de Glicerina Por Reação Com Um Agente Eterificante. PI 0806066-5 A2, September 10, 2010.

(38) Dos Santos, A.; Miranda, F.; Brito de Oliveira, O.; Mayan, R.B.; Dourao, E. Processo de Eterificação Da Glicerina Bruta Para Geração de Aditivos Verdes Oxigenados. BR102012016829, June 10, 2014.

(39) Khadzhibekov, S.N.; Tulyaganov, S. R.; Sultankulov, A.; Kadyrov, Ch. Sh. Some Aspects of Synthesis of 1,3-Dialkoxy-2-Propanols. Doklady Akademii Nauk UzSSR 1985, No. 3, 40-41. 